\title{
Evolution of Peak Palace-Fortress in Tibet: The Reappearance of the Sangzhutse Palace-Fortress and Design of the Fortress Museum
}

\author{
Qing Chang \\ College of Architecture and Urban Planning, Tongji University, Shanghai, China \\ Academician of Chinese Academy of Sciences
}

\begin{abstract}
The dzong fortresses were the typical buildings for the unification of religious and governmental rulers in old Tibet. The archetype of the dzong fortress can be dated back to the 2nd century BC and evolved into those fortresses built on the top of the holy mountains. The Sangzhutse Fortress, popularly called 'Little Potala', was a hilltop building located in the centre of Shigatse city and was the grandest landmark among all local dzong fortresses of Tibet since the $14^{\text {th }}$ century. It acted as the commanding point of the city skyline, and the spiritual anchor for the locals. Unfortunately, it was destroyed during the political turmoil in the 1960s. From 2004 to 2010, under the sponsorship of the Shanghai Municipal Government in cooperation with the local Tibetan authority, the team of the Design Institute of Tongji University completed research work of the dzong fortress, developing the whole design from the initial sketches to building construction plans, and surveying the construction process. The consolidation of the remaining structure and the restoration of the original skyline of the fortress were achieved through the organic combination of local traditional materials and crafts with new building technologies, producing a new living landmark of Shigatse city while maintaining its remains. The interior space, designed as the first museum in Shigatse and Western Tibet, was opened in 2010.
\end{abstract}

KEYWORDS The Sangzhutse Fortress, evolution, restoration, revitalisation, folk-art museum

The Sangzhutse Fortress, popularly called 'Little Potala', was a hill-top fortress landmark in the centre of Shigatse city in Tibet that acted as the commanding point of the city. In terms of scale and grandeur, the Sangzhutse Fortress was only second to the Potala Palace in Lhasa, which was completed 330 years after the Sangzhutse Fortress. Unfortunately, the Fortress was destroyed during the political turmoil in the 1960s. In 2004, with the support from the Shanghai Financial Aided Program Office for Tibet and Xinjiang, both the local department for cultural administration and the social organisations of Shigatse city sought to rebuild the Fortress as the local Tibetan folk-art museum. In the following three years, Chang Qing Studio and the Design Institute of Tongji University took charge of 'The Preservation and Restoration of the Sangzhutse Fortress' project. Today, the destroyed fortress has been returned to Shigatse as a landmark of the city and a spiritual anchor for the Tibetan people, as it once was in history.
The significance of this project lies not only in the preservation of the ruins and the physical recovery of the demolished structure, but more so in the restoration of spirit, especially that of the psychological landmark that was destroyed in modern times. Perhaps of even greater significance is the contribution of the project to revitalise the local culture through the preservation and restoration process. While it was both necessary and feasible to reconstruct what had been destroyed in order to return what had been lost, the process took rigorous references to the principle of authenticity to revive the symbolic value of a spiritual place and return the typological value of an architectural monument.

The project aims to revive and sustain the vital landscape of Shigatse city through the recovery of its urban historical skyline. The project is also a response to the emotional appeal of the local Tibetan people, who for many years have made proposals for reconstruction to the city council. The functional role of the restored fortress as 


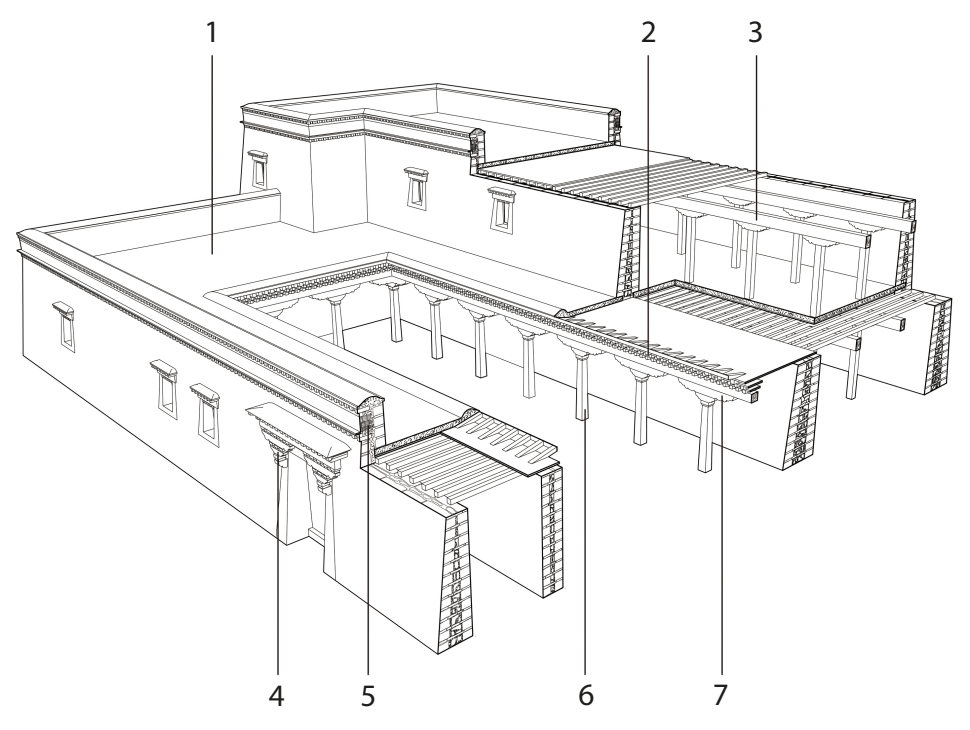

Figure 1 Illustration of typical Tibetan blockhouse (Source: Chang Qing Studio)

1. Aga clay flattop paving;

2. Fly rafter;

3. Longitudinal plane ribbed structure;

4. Sopraporta: cornice, which is a combination of Chinese brackets and Tibetan corbels;

5. Bianma wall;

6. Tibetan Column;

7. Corbel. a folk-art museum, the first of its kind in Tibet, will play a significant role in preserving and sustaining the local traditional cultures.

\section{Dzong Mountain System}

Shigatse is the second largest city in the Tibet Autonomous Region of China and is located in the centre of Tibet. It became the seat of successive Panchen Lamas (from the fourth Lama onwards) since the late Ming Dynasty (1368-1644). In addition, Shigatse was once the political centre of Tibet starting from the end of the Yuan Dynasty (1271-1368) and the beginning of the Ming Dynasty. According to historical documents, such as Yuanshi Baiguanzhi (Records of Officials in the History of the Yuan Dynasty), the central government of China began to administrate Tibet during the Zhizheng reign (1341-1370) of the Yuan Dynasty (Sima 2000). A taisitu (the local governor designated by the central government) by the name of Changchub Gyaltsen (1302-1364), from the Tibetan upper-class Lang family, led the Pazhu Gagyu faction to replace the Sagya faction as the governing regime recorded by the book The History of Lang Family written in the Yuan Dynasty (Changchub Gyaltsen 1989). They abolished the 'Ten-Thousand Household System' and divided Tibet into 13 large dzongs (religious administrative units). Meanwhile, they moved the political centre from Shalu to present day Shigatse, and built large fortified buildings known as 'Shika Sangzhutse', which was simplified to 'Shikatse', from which derived the name of the city 'Shigatse'.

The word dzong was originally used to name architecture in the form of forts or baozhai (fortressed village), and later became the reference of local governments and their locations. These buildings can also be called 'palace fortress', 'dzong palace' and so on, which all refer to baozhai or hilltop citadels that are combined by blockhouses (Figure 1) and fortresses. If the government building of a dzong is located on a mountaintop that faces a river, then it is called 'dzong mountain'. A relatively complete example is the dzong mountain in Gyantsé (Figure 2), and dzong palace sites exist in Gonggar, Dinggyê, Qusum, Pali, etc (Figure 3).

\section{Sangzhutse Fortress and Potala}

Historical documents and paintings (mainly Thangka of Tibet) show that the Sangzhutse Fortress and the Potala Palace closely resemble one another in form and aesthetics. As a whole, they both have a middle section which is slightly higher than the wings, and are similar in parts such as the round fort in the West. Besides, they both have a red palace (political-religious holy space) in the centre flanked by two white palaces (administrative space for monks and laymen).

In fact, the Sangzhutse Fortress was constructed even earlier than the Potala Palace: about 285 years earlier than the white palace which was constructed in 1645 and 330 years earlier than the red palace which was constructed in 1690. Consequently, it is popularly believed that the Potala Palace was influenced directly in design by the Sangzhutse Fortress.

The earliest illustration of the Potala Palace which exists today is a woodblock by a German named Athanasius Kircher (1602-1680) based on the travel notes by an 


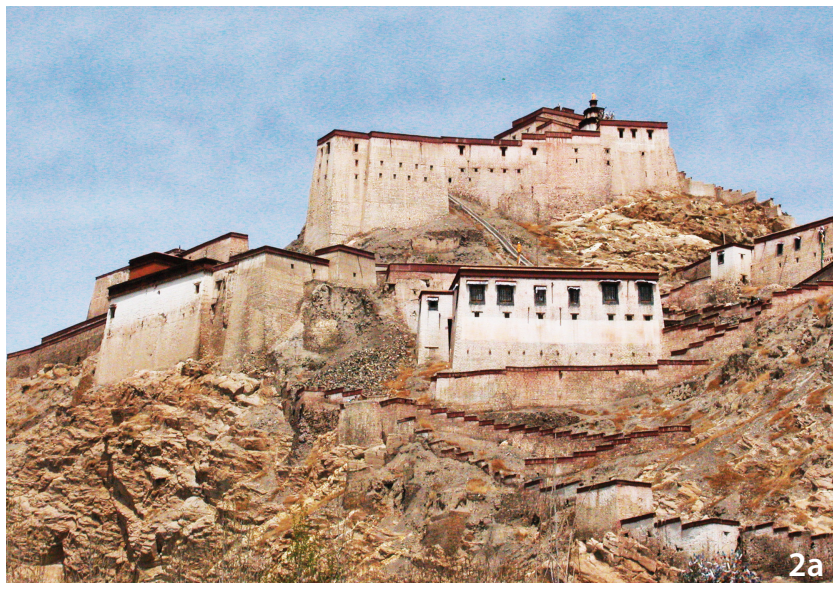

Figure 2a Skyline of dzong mountain in Gyantsé (Source: the author). Figure $\mathbf{2 b}$ the interior of the dzong palace (Source: the author).

Figure 3 The relics of the dzong palace in Gonggar (Source: http://blog. sina.com.cn/s/blog_461120cb0100krwn.html).
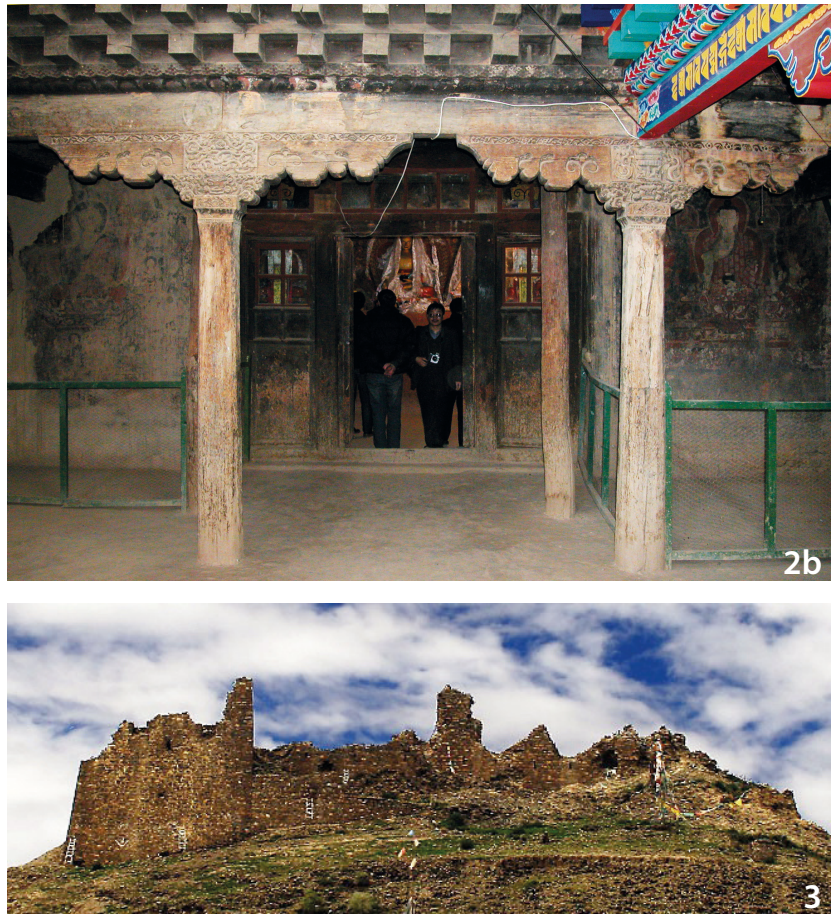

red palace of the Sangzhutse Fortress, reflecting the difference in political and religious positions of the two palaces (Figure 7, Figure 8). Although the Sangzhutse Fortress was smaller than the Potala Palace in size, it nevertheless scaled an impressive height of $92 \mathrm{~m}$ at its peak point from the foot of the mountain, and it spanned $230 \mathrm{~m}$ across. The fortress had an internal area of $5,880 \mathrm{~m}^{2}$

About 560 years later after it was built in Yuan Dynasty, there was a big rehabilitation made by the local government during 1922-1925. Almost all photographical evidence of the fortress was taken after that. Therefore, our main question was to what extent this rehabilitation had changed the historical form of Sangzhutse Fortress. This is related to the basis for the restoration of the skyline, which also means whether the skyline was changed after that important rehabilitation. Fortunately, we discovered an image taken by a Swedish explorer Sven Anders Hedin who came to Shigatse in 1907. The image provides credible evidence of the appearance of the Fortress before the rehabilitation (Figure 9). Moreover, we found an important colour painting drawn in 1902 by an Indian scholar Sarat Chandra Das, which clearly illustrates the red-white coloured wall of the Sangzhutse Fortress (Figure 10). From the photo and painting, we confirmed that the forts and palace of the Sangzhutse Fortress are roughly the same as the photos taken by the German scholar Ernst Schäfer (1910-1992) at the end of the 1930s after the big rehabilitation and those taken by the famous photographer Chen 

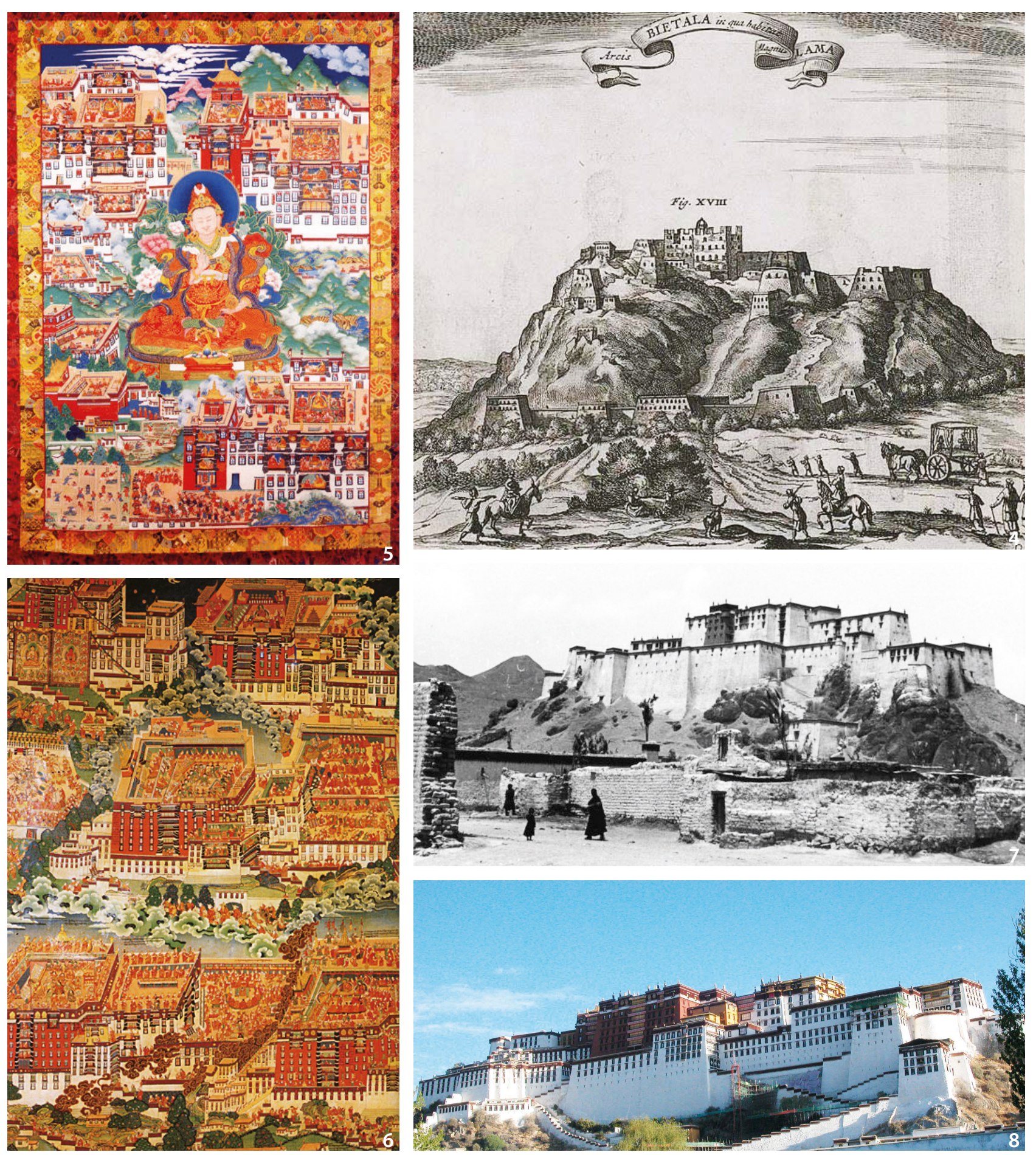

Figure 4 Illustration of Polata Palace in China Illuserata (Source: Kircher 2010).

Figure 5 Potala Palace in the Thangka from $17^{\text {th }}$ century (Source: http://mt.sohu.com/20150213/n409001492.shtml).

Figure 6 Wall painting in Potala Palace showing the scene of the completion of its Red Palace (Source: http://mt.sohu.com/20150213/n409001492. shtml).

Figure 7 Picture of Sangzhutse Fortress taken by Ernst Schäfer during the 1930s (Source: https://commons.wikimedia.org/wiki/File:Bundesarchiv_ Bild_135-S-17-22-34,_Tibetexpedition,_Shigatse,_Burg.jpg\#).

Figure 8 Polata Palace (Source: the author). 


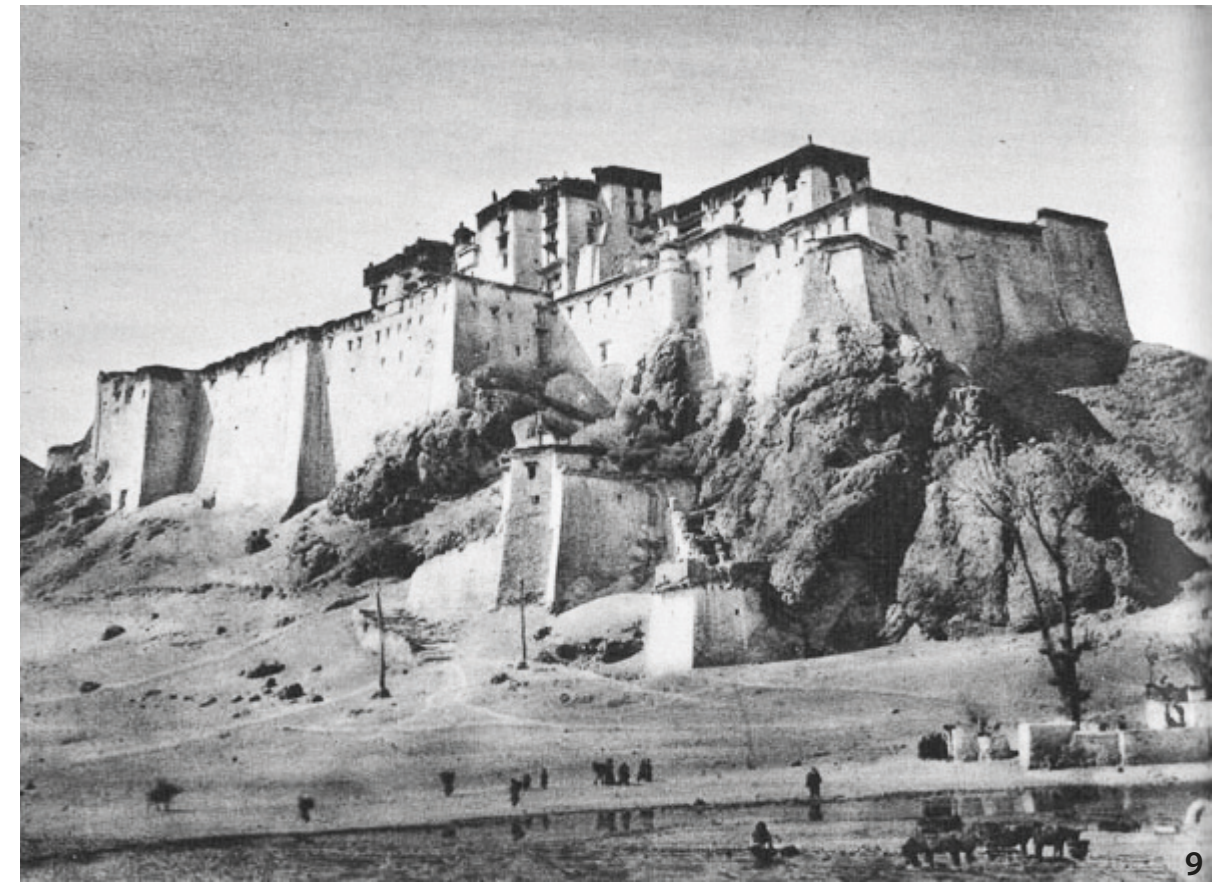

TOWN OF SHIGATSE.

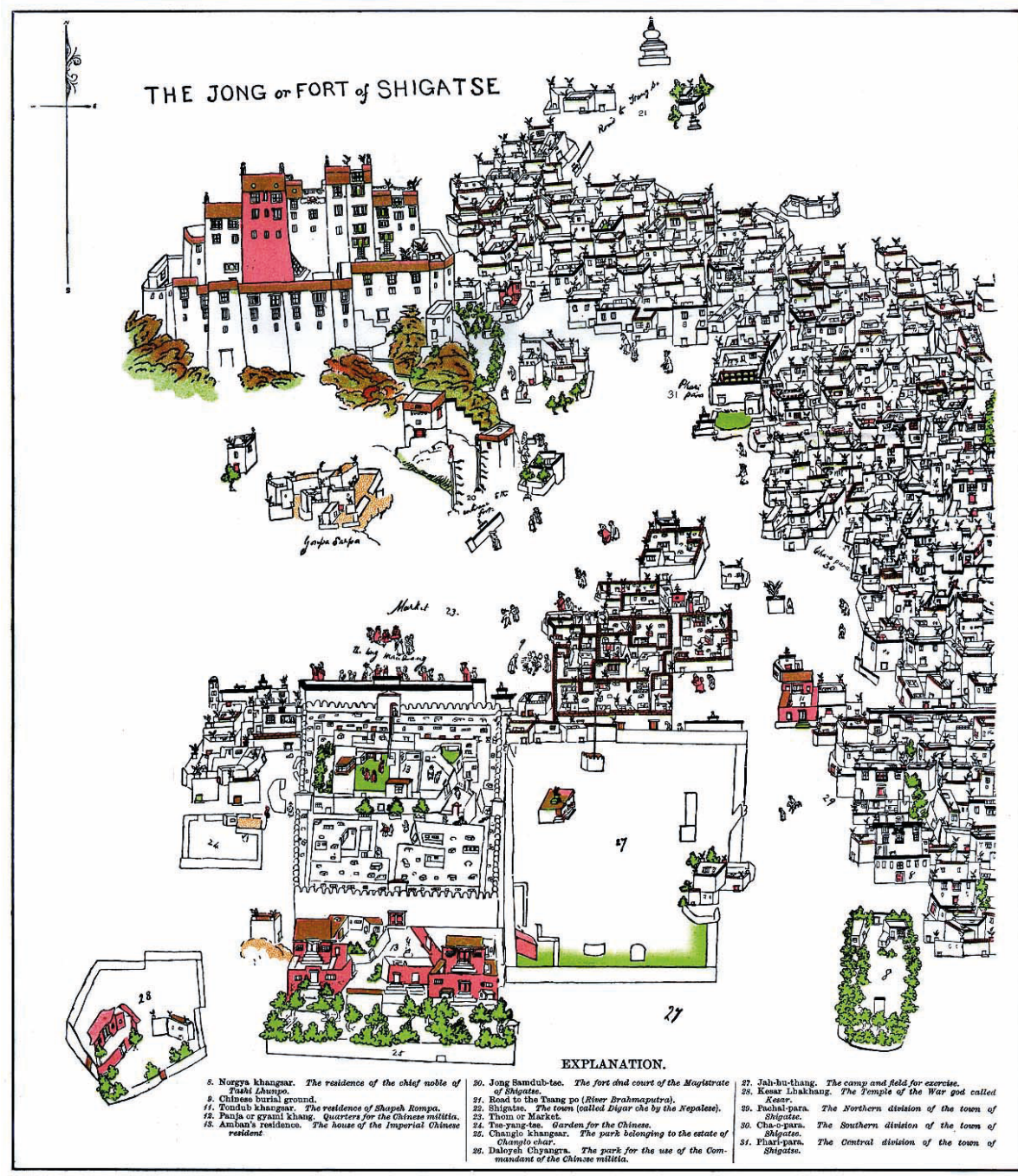

Published by the Royal Geofraphical Society
Figure 9 Picture of Sangzhutse Fortress in the article, 'My Discoveries in Tibet' (Source: Hedin 1908).
Figure 10 Sangzhutse Fortress in Shigatse from a drawing in 1902 (Source: 10 Das 2005). 

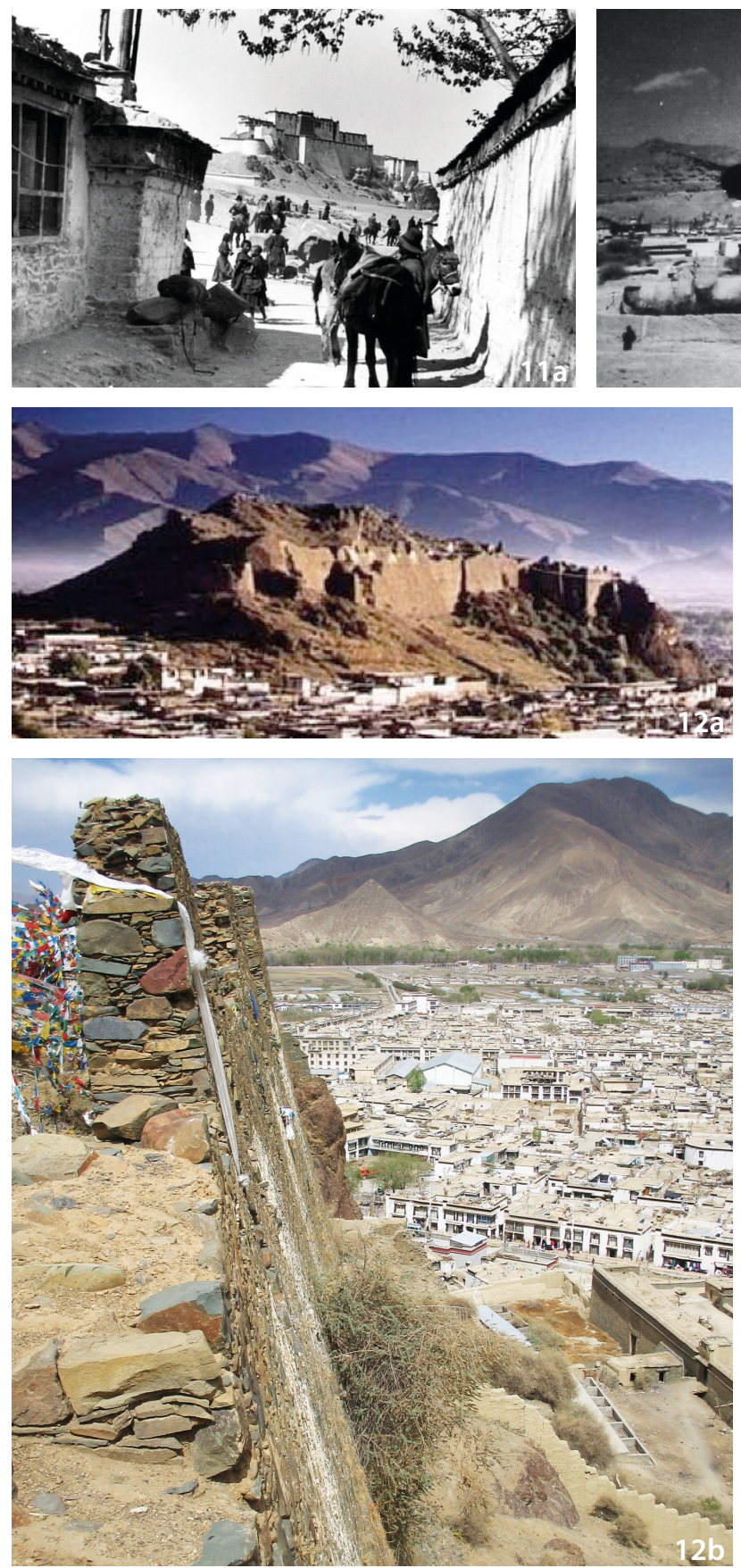

Zonglie in the 1950s who worked in Tibet. This proves that there was just a slight difference between the images before and after the 1922-1925 rehabilitation (Figure 11).

During the 1960s and the Cultural Revolution, the Sangzhutse Fortress was seen as a hated symbol of past serfdom, and in 1968, it was demolished and destroyed to ruins by the former serfs. The palace was torn down, with all the timber components such as the columns, architraves, ribs, dougong, doors and windows removed and the base destroyed, leaving only the ruins of the fortress platform (Figure 12).
Figure 11a Photo of Sangzhutse Fortress and the village taken by Ernst Schäfer in 1930s (Source: https://commons.wikimedia.org/wiki/ File:Bundesarchiv_Bild_135-S-17-26-30,_Tibetexpedition,_Blick_auf_ Burg.jpg)

Figure 11b Photo taken by Chen Zonglie during 1950s (Source: Chen Zonglie).

Figure 12a Paramona of the Sangzhutse Fortress after destruction (Source: Shigatse Region Administration)

Figure 12b Ruins of the Sangzhutse Fortress wall (Source: the author).

It has taken some 40 years after its destruction before it returned to life through major restoration. As a physical and spiritual landmark of Shigatse city, the restored Sangzhutse Fortress is used as a folk-art museum-the only one of its kind in Tibet-with exhibitions that focus on the historical transformation of the building, cultural relics, local folk crafts and art works.

\section{The Restoration Project}

The whole project took three years and was carried out in three stages.

Stage 1: Historical Research, Site Survey and Investigation of the Ruins (from April 2004 to July 2004). The project team went to the Qinghai-Tibet Plateau for the first time during this stage, returning to Tibet more than ten times in the later years, investigating the site repeatedly and collecting historic materials. The ancient works of Tibetan literature translated and explained by local Tibetologists were studied carefully. During the investigation process, several historical pictures were discovered by the team.

Stage 2: Architectural Design (from May 2004 to February 2005). The design integrated the preservation of the surviving ruins and the reconstruction of the destroyed parts of the fortress on its original bearing platform (Figure 13). The final design scheme was approved by a national appraisal committee consisting of experts and administrators for conservation. The design development and the working drawings were finished during the following six months. 

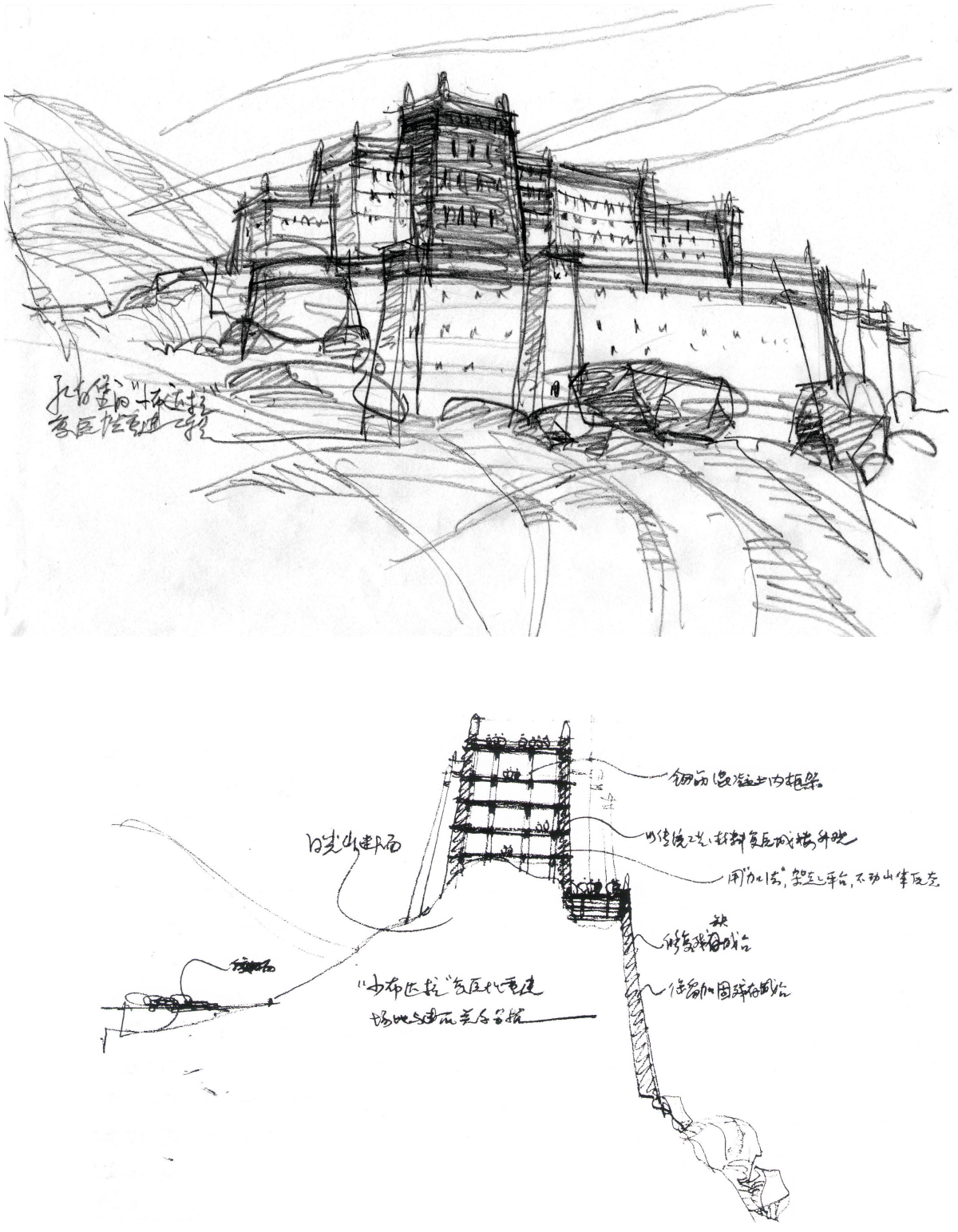

1. The White Palace;

2. The Red Palace;

3. The White Palace;

4. Deyang Building;

5. West Plaza;

6. East Plaza

Reconstructed Part

Remained Part

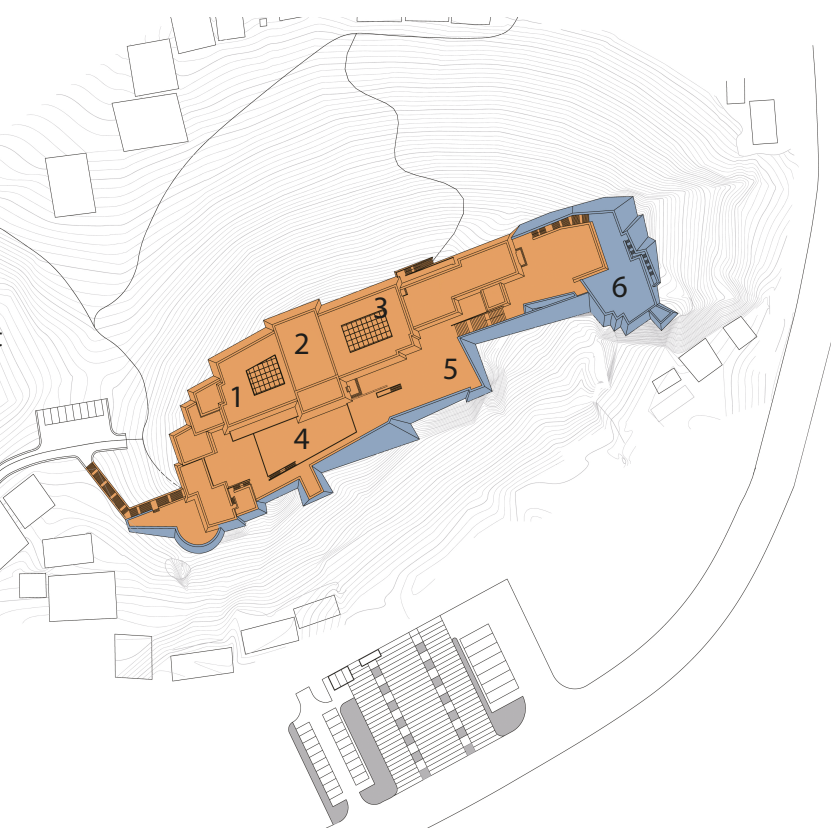

Figure 13a Sketch of restoration concept for the Sangzhutse Fortress (Drawn by the author).

Figure 13b Section of Sangzhutse Fortress (Drawn by the author). Figure 14 The plan of the Sangzhutse Fortress after restoration (Source: Chang Qing Studio). 


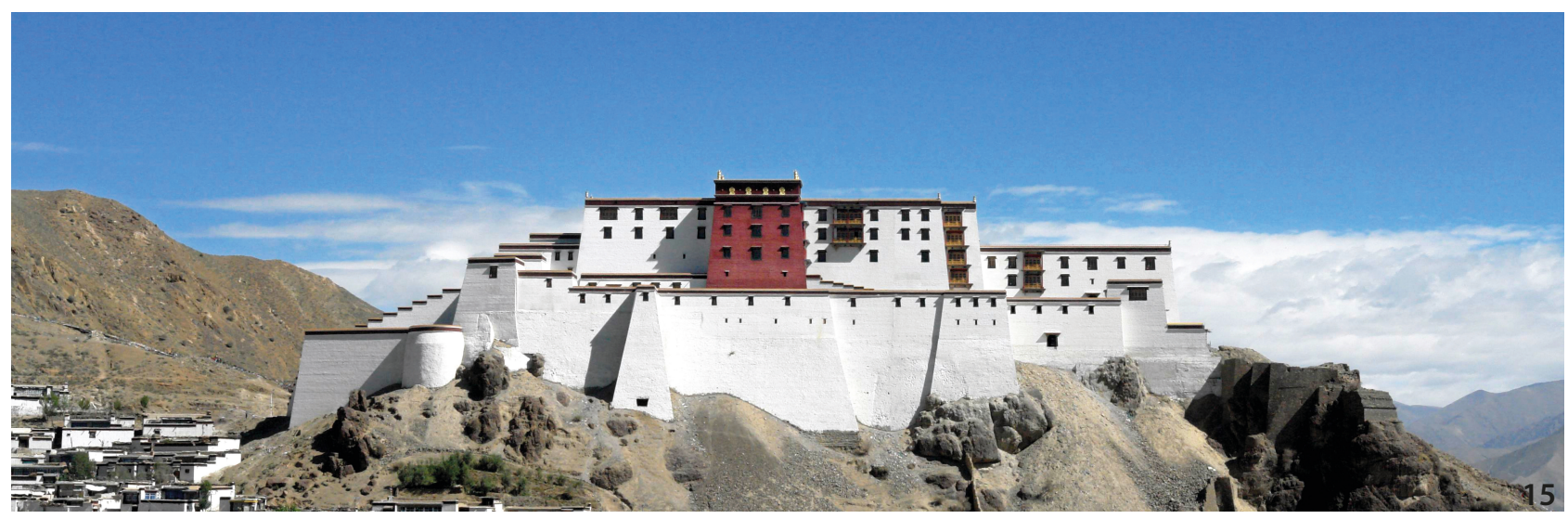

Figure 15 Sangzhutse Fortress after restoration (Source: Zhang Siye).

Stage 3: Construction (from March 2005 to March 2007). The height of the Tibetan Himalaya and the complicated terrain of the site brought many problems for the project. For example, it was very difficult to bring large construction machines to the site, but this was resolved by disassembling the machines for transport and reassembling them on site. The constant danger posed by the site work is exemplified by the unfortunate death of an engineer in the project team, who succumbed to altitude sickness.

The restored fortress is a four-storey structure with a dimension of $230 \mathrm{~m}$ in width, $92 \mathrm{~m}$ in height from the bottom of the mountain and a floor area of 7,442 $\mathrm{m}^{2}$. The construction cost was 12 million CNY (Figure 14).

\section{Articulation of Heritage Values and Significance}

As a historic monument, the 650-year-old fortress is a significant cultural heritage of Tibet and a significant collective memory of Shigatse city. It forms a significant part of the cultural landmarks and landscape of Shigatse city as well as of the Tibet. It is a masterpiece of $d z o n g$ fortress architecture, which is believed to have influenced the magnificent architecture of Potala. It is also one of the most important spiritual anchors for the local Tibetan people, and it has formed an indispensable part of the city skyline and part of the memories of the locals for some 650 years. Before its destruction, the fortress had been used continuously by the local people as a place of worship and pilgrimage. As ruins of fortress stone wall and masonry technique, it carried research value for historians and conservationists. However, as a complete building, the restored Sangzhutse Fortress with its rehabilitated new uses has incurred greater educational value to the local community and visitors.

\section{Appropriate Use}

Symbolically, the restored Sangzhutse Fortress becomes an iconic landmark in the city's skyline; culturally, it serves as a Tibetan folk-art museum that exhibits Tibetan cultural relics, folk art and folk crafts (Figure 15). The original historical fabric of the Fortress has been carefully preserved, with only the necessary reinforcement to fulfil safety requirements. Based on historical research, the restored parts of the fortress have been constructed with traditional materials and techniques. There were two key parts of construction: the lower terrace that had partially survived the destruction during the Cultural Revolution, and the upper superstructure that had been demolished to a state of ruin.

The architectural space of the restored fortress emphasises on 'multi-functional cultural synthesis', which is dominated by the historic exhibition. The trapezoidal 'Deyangshar' courtyard located at the south of the fortress can be used for holding such religious celebrations as the annual 'Guduo Festival', during which the Panchen Lama gives sermons on a platform. Other courts and open grounds provide circulation spaces of a large number of people. The red palace in the centre of the fortress contains exhibition spaces and a worshipping hall, while the white palaces on both sides contain exhibition and service spaces (Figure 16, Figure 17).

\section{Technical Issues in the Restoration Process}

In the schematic design phase, new technologies such as GIS and 3D visual techniques were employed to precisely match the restored skyline with the historical one. The next stage combined advanced information technology with local low-tech techniques to preserve and stabilise the surviving fortress ruins, with minimal interventions 


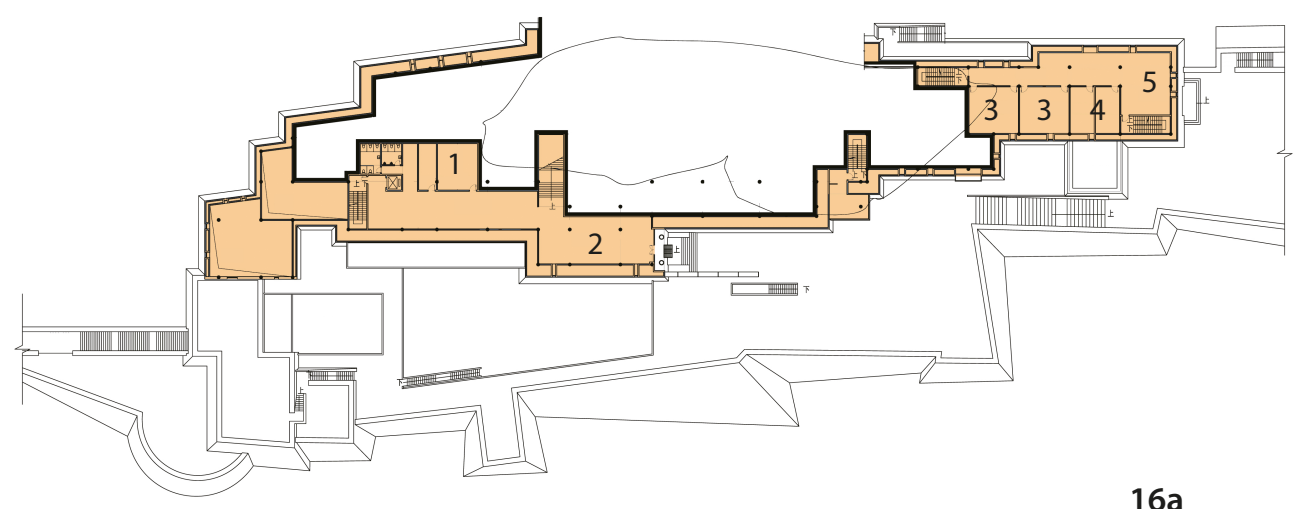

$16 a$
Figure 16a The plan of the top floor and the first floor (Source: Chang Qing Studio).

1. VIP Room;

2. Entrance hall;

3. Reading room;

4. Research room;

5. Rest area;

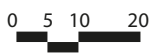

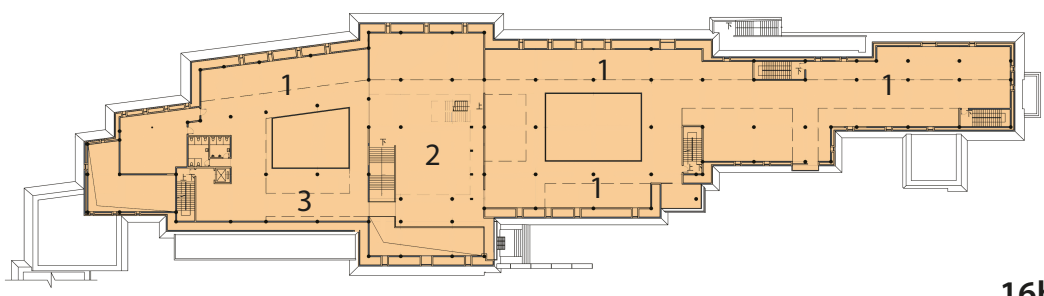

Figure 16b The plan of the second floor (Source: Chang Qing Studio).

1. Exhibition area;

2. Atrium;

3. Gallery.

$16 b$
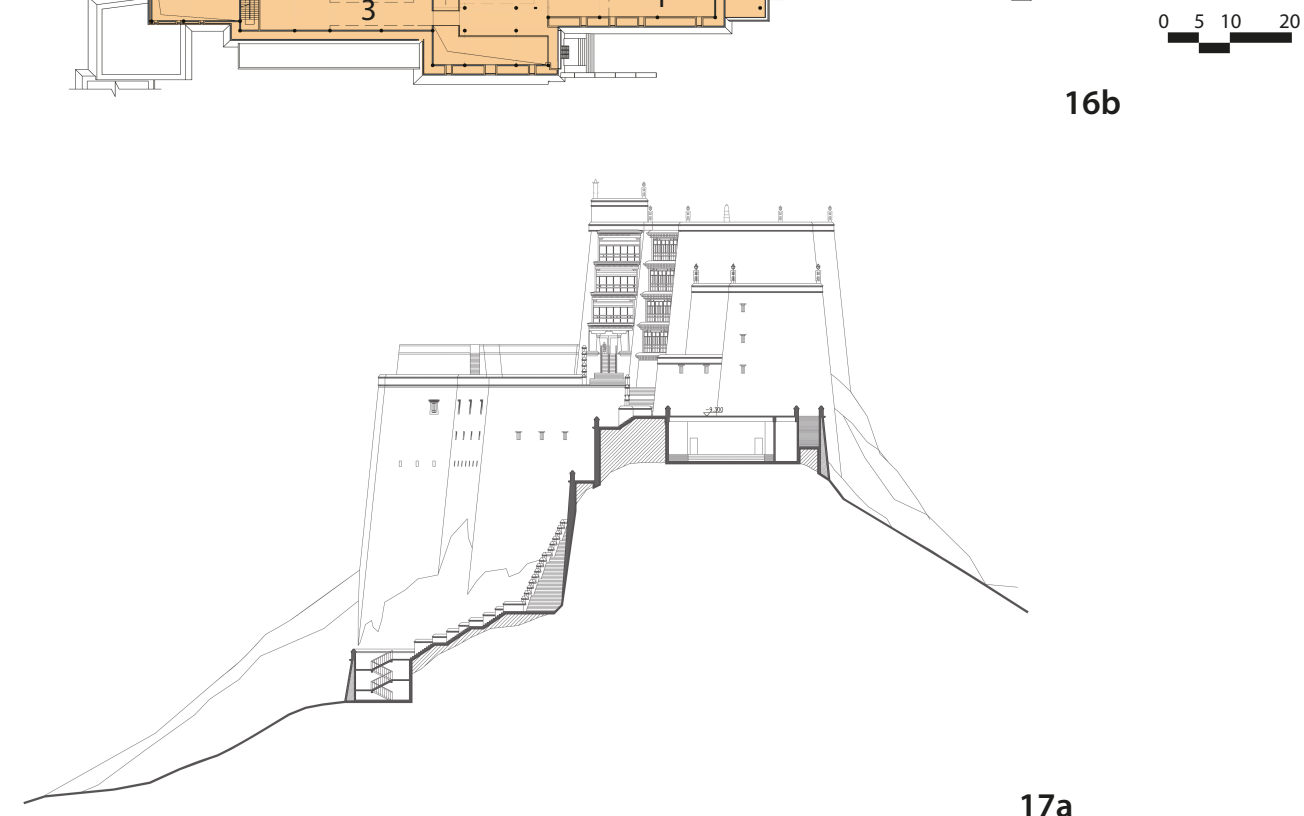

$17 a$

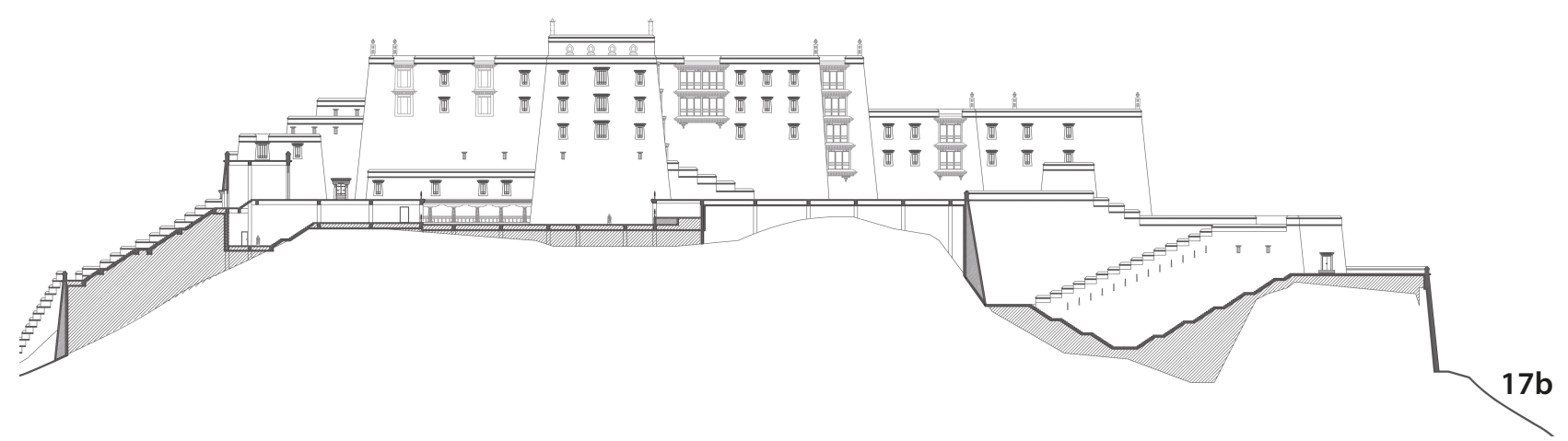

Figure 17a The cross sections of the Sangzhutse Fortress (Source: Chang Qing Studio).

Figure 17b The longitudinal sections of the Sangzhutse Fortress (Source: Chang Qing Studio). 

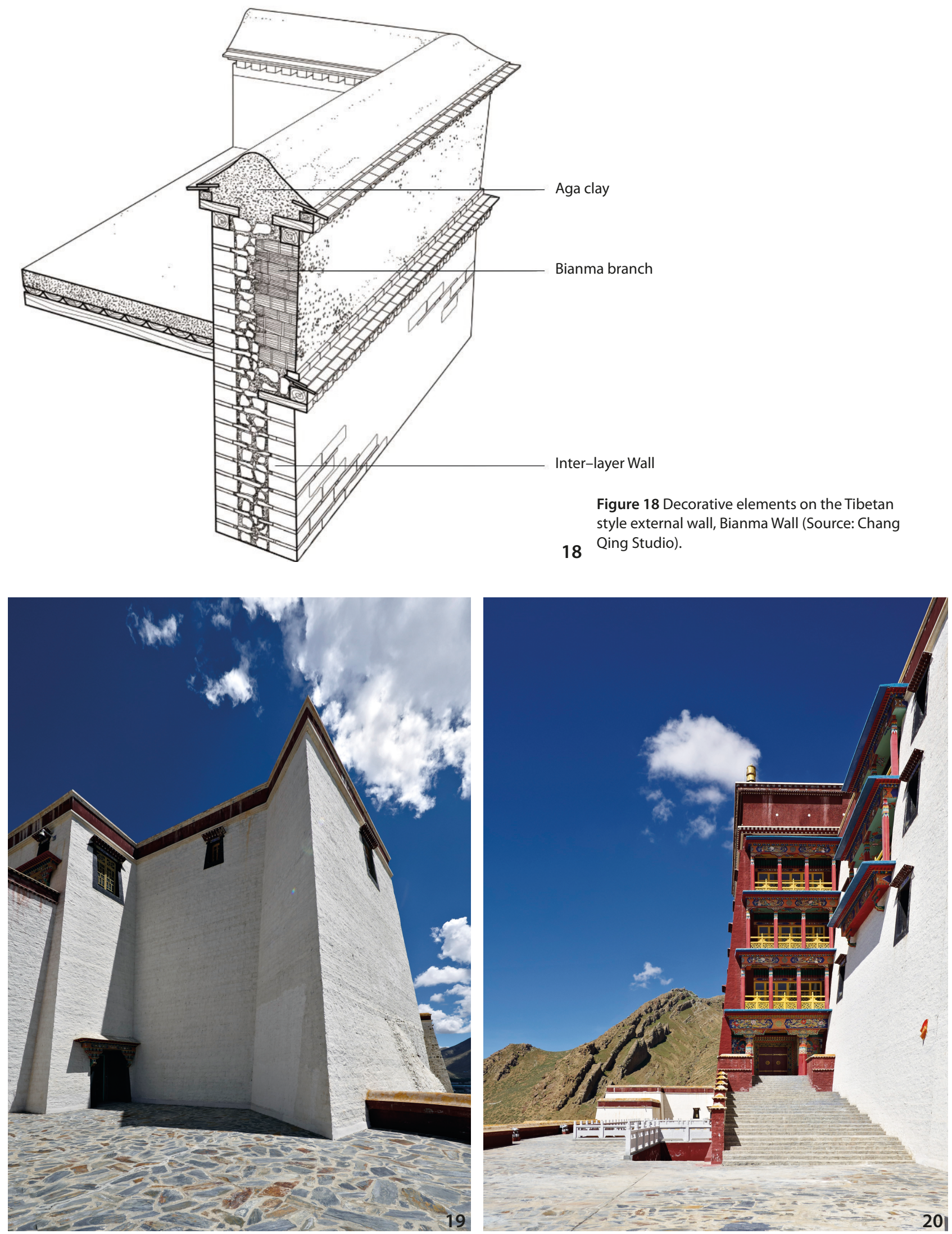

Figure 19 The southeast corner of the white palace of the Sangzhutse Fortress after restoration (Source: Zhang Siye). Figure 20 Entrance of the red palace of Sangzhutse Fortress after restoration (Source: Zhang Siye). 

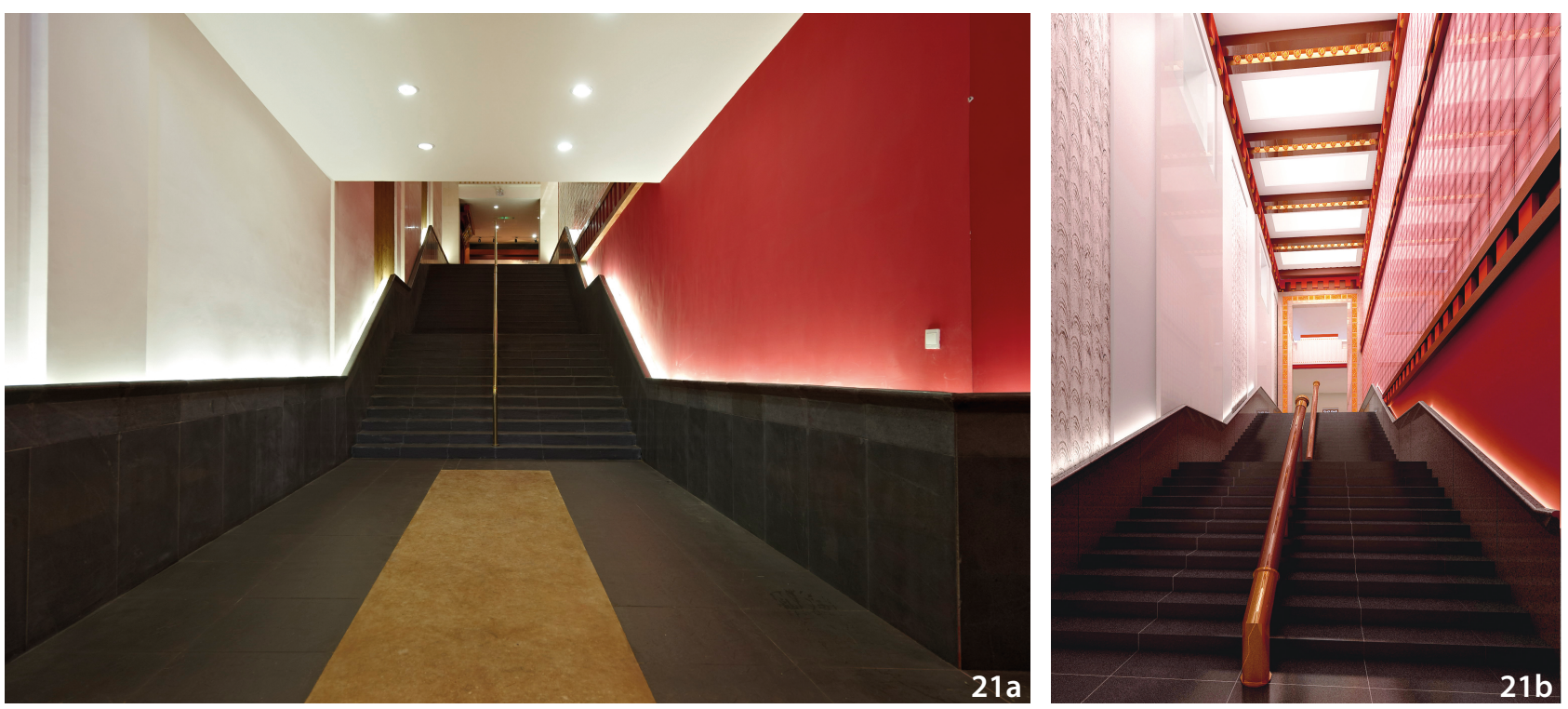

Figure 21a The hall in the Sangzhutse Fortress I (Source: Zhang Siye). Figure 21b The hall in the Sangzhutse Fortress II (Source: Zhang Siye).

taken only when safety is of concern.

Based on historical research, the demolished portion of the fortress was reconstructed in the traditional manner, using local traditional materials and techniques as far as possible, so as to integrate the new reconstruction with the preserved ruins. Although reinforced concrete was necessarily required in the critical load-bearing internal structure, all external architectural elements followed exactly the traditional materials and techniques used in the construction of a fortress. Local Tibetan craftsmen were involved in the restoration process.

The historical red and white palaces were rebuilt with new additions. What had been the ruins were preserved in its current appearance with no alteration to its shape and colour.

For architectural elements that have no pictorial reference to verify from, such as the entrance gate, windows on the sides and ramp roads, reference was made to the design of similar elements in other comparable Tibetan fortresses.

\section{Application of Appropriate Building Materials and Techniques}

The design of the reconstructed building is based on detailed analysis of the site and the cultural character of Tibet in terms of religious symbolism of architectural decorations, types of finishing material and architectural details.

Such details include door and window mouldings; projecting eaves over doors and windows with double or triple rafters; multisets of Tibet-style brackets underneath the grand porch; the Shangbu made of red, white and blue cloths between the window and eaves.

The doors and windows all have $30-40 \mathrm{~cm}$ wide black frames that are wider at the bottom and narrower at the top, a configuration that conforms to the canting façade. Great attention has also been paid to the specific differences between the window frame design of different parts of Tibet, as well as the religious ornaments that appear on the cornices of the red complex, such as, the scripture pillars and streamers made of metal, fabric and wool (Figure 18-20).

The restored fortress appears with red and white walls, while the southeast corner remains in its original ruinous appearance after consolidation works for safety. The walls and floors are faced with local stones and wood. Local Tibetan craftsmen have been employed to apply traditional Aga clay paving in the building. This traditional construction material and technique used in the building interior will also serve to showcase the traditional local material and its application (Figure 21).

\section{Integrating and Distinguishing Old and New}

The ruins of the Sangzhutse Fortress consisted of underground remains and above-ground vestiges of the original fortress. Owing to the high and steep cliff and complicated terrain of the site as well as respect for the natural environment and Tibetan culture, we adopted a restoration 


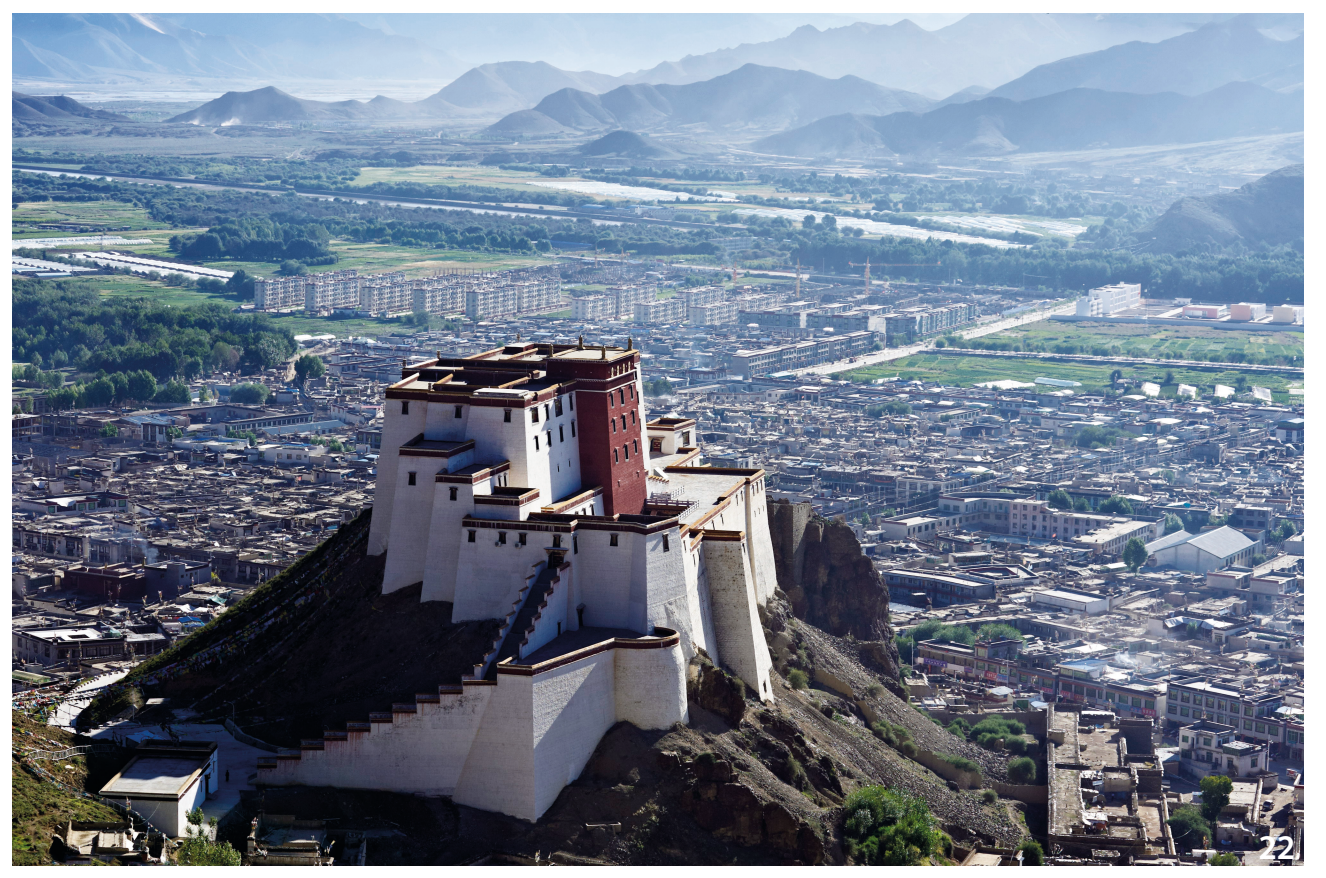

Figure 22 Skyline of the historic centre of Shigatse after the restoration of Sangzhutse Fortress (Source: Zhang Siye).

approach in accordance with local Tibetan dzong mountain designing customs. The ruins were reinforced and stabilised, and the damaged terrace was repaired and restored with traditional materials and technique. Then, as much of the original stone walls were preserved and repaired with distinguishable but compatible new materials.

As in the traditional way of construction in Tibet, the restored building was laid out by conforming to the undulation of the terrain, with guiding reference from historical images to ensure that the restored fortress superstructure would appear as faithful as possible to its original model. The reconstruction of the superstructure was carried out in accordance with traditional materials and techniques so that the restored fortress would capture the essential appearance and spirit of the original. A portion of the original ruins has been left in its ruinous state to give comparative reference of both as a part of the whole restored and maintenance of the ruins.

\section{Impact of the Project}

This project was supported by local Tibetans emotionally and practically. For instance, local craftsmen were involved in the restoration process while local residents offered assistance during the initial site investigation and subsequent restoration. They also prayed devoutly for the success of the project. The local public has been motivated by the project to participate more actively in conservation activities by means of learning the techniques required for future maintenance. For local young people, the project has helped in the rediscovery of their Tibetan cultural identity by connecting them with history and tradition. The sight of the completed fortress has revitalised the memories of older members of the community and energised their spiritual connection with the place.

The project has returned to Shigatse city its original historical skyline (Figure 22). This geographical restoration has helped in re-establishing the cultural and spiritual relationship between the Sangzhutse Fortress and the Tibetan topography, as well as the collective memory of the place in the context of Tibetan culture and socio-history.

As a local elderly Tibetan woman named Mrs Chey recalled, before its destruction, the original Sangzhutse Fortress was used as a forbidden sentencing court with basement prison cells for the enslaved Tibetan people. The fortress, therefore, carried the negative symbols of past serfdom and punishment and was a place of terror for children. The restored fortress, now opened to the public with a folk-art museum, is a positive symbol of the future to local Tibetans, including Mrs Chey.

Besides its social, cultural and spiritual benefits, the restored fortress is a potential catalyst for economic development through cultural tourism.

\section{Conclusion}

The basic principle of 'respecting the original state' is interpreted in two ways in this project. One is to respect the original physical state, which is the ruins; the other is to respect the original spiritual state, which is expressed 
within the social, cultural and spiritual context of the city. Both aspects have been considered and applied to different parts of the restored building.

Respect for the physical original state is achieved by means of maximum retention of the original fabric of the fortress remains, with minimal necessary interventions taken out of safety concerns. To show respect to authenticity, all new additions are distinguishable from the old fabric in terms of material texture, shape and style.

Respecting the spiritual original state is achieved by means of returning the ruined fortress to its complete state, which was as much a landmark in the geographical landscape as an anchor in the spiritual mindscape as a place of worship and pilgrimage. To restore this spiritual quality, the authenticity of the restored building is critical to evoke the spiritual collective memory of the local people, and this is achieved through accurate research data and rigorous application of local traditional materials and techniques. Tibetan craftsmen were employed to re-create authentic Tibetan architectural ornamentation that embodies a rich symbolism with which only local craftsman would be familiar.

Attention has also been paid to the collective memory of local Tibetan people. In this regard, the project team interviewed a sizable number of elderly people who were familiar with the original fortress to find out information such as entrance doors, side windows and the ramp roads-detailed information that could not be ascertained in the absence of the historical photographic reference. Hence, oral history is an important method to build up the detailed architectural database for an authentic restoration plan.

In the city scale, the project team sought to return the original historical skyline to Shigatse city through the restoration of the fortress. An accurate representation of the fortress form in the natural terrain is important. This was achieved by mapping the historical form onto the natural terrain and letting the existing site levels determine the recreated interior architectural layout (which has made reference to compatible buildings in Tibet). The project will be recorded in the Tibetan annals as a significant cultural event in Tibet. ${ }^{1}$

\section{Notes}

1. The project won the 2008 Gold Award in Architectural Design in Shanghai, 2011 Gold Award of National Design in Beijing and the Gold Medal of the Architects Regional Council Asia Award for Architecture in 2015.

\section{Acknowledgement}

This project was designed by Tongji Architectural Design (Group) Co., Ltd. Chang Qing was the principal architectural designer of the project who took charge of the historical research, conceptual design, and the control of the overall design process. Ding Jiemin was the principal structural designer and the chief coordinator of the overall construction process. Hua Yun was the supervisor of the construction drawings. Special thanks also go to the team members who made great contributions to the projects. They are Du Wenhua, Gong Jin, Hu Tao, Wan Yuerong, Xie Wenli, Yan He, Yao Wei, Yin Yong, Yu Wenbin, Zhang $\mathrm{Xu}$, and $\mathrm{Zhou} \mathrm{Jin.}$

\section{References}

Chang, Q., Yan H. and Yin, Y. 2015. “The Revival of Little Potala: The Research on The Restoration Proposals For The Sangzhutse Palace-Fortress In Shigatse." Architectural Journal 12: 45-47.

Chang, Qing. 2011. "Historic Evolution of the Sangzhutse Palace-Fortress and Its Restoration Project." Architectural Journal 5: 1-8.

Chang, Qing. 2014. Envisioning Historic Place: Urban and Rural Architectural Conservation Field at Tongji University. Shanghai: Tongji University Press.

Changchub, Gyaltsen. 1989. Lang Shi Jia Zu Shi [History of the Lang Family]. Translated by She Wanzhi and Zanah Ngawang. Lhasa: Tibet People's Publishing House.

Das, Sarat, Chandra. 2005. Journey to Lhasa and Central Tibet. Translated by Guansheng Chen and Peimo Li. Beijing: China Tibetology Press.

Hedin, S. 1908. "My Discoveries in Tibet." McClure's 117: 67-69

Hedin, Sven. 2000. Trans-Himalaya: Discoveries and Adventures in Tibet. Translated and edited by Jingping Bao. Urumqi: Xinjiang People's Publishing House.

IHNS (Institute for History of Natural Sciences). 1985. Zhong Guo Gu Dai Jian Zhu Ji Shu Shi [History of Ancient Chinese Architectural Technology]. Beijing: Science Press.

Kircher, Athanasius. 2010. China Illuserata. Translated by Zhang Xiping, Yang Huiling and Meng Xianmo. Zhengzhou: Elephant Press.

Krull, D. 2005. Memento Frauenkirch: Dresden's Famous Landmark as a Symbol of Reconciliation. Berlin: Verlag Bauwesen.

Owang Saosang Gyatso. 1983. Bod kyi deb ther dpyid kyi 
rgyal mo'i glu dbyangs [A History of Tibet by the Fifth Dalai Lama of Tibet]. Translated and edited by Heqin Guo. Beijing: Publishing House of Minority Nationalities.

Sima, Qian. 2000. Shi Ji [Records of the Grand Historian]. Beijing: Zhonghua Book Company.

Sonam, Gyaltsen. 1985. Rgyal rabs gsal ba'i me long [Clear Mirror on Royal Genealogy]. Translated and edited by Liqian Liu. Lhasa: Tibet People's Publishing House.

Song, Lian. 1976. Yuan Shi [History of Yuan Dynasty]. Beijing: Zhonghua Book Company.

Taranatha. 2002. Hou Zang Zhi [Annals of Tibet]. Translated by Wanzhi She and proofread by Ngawang. Lhasa: Tibet People's Publishing House.

Wan, Yuerong, and Gong, Jin. 2005. Restoration Project of Sangzhutse Palace-Fortress. Tongji Architectural Design (Group) Co., Ltd.

Xi Zang Ji [Record of Tibet]. 1985. Beijing: Zhonghua Book Company.

Yin, Weixian. 2000. Ming Dai Zang Zu Shi Yan Jiu [Research of the Tibetan History in Ming Dynasty]. Beijing: Publishing House of Minority Nationalities. 